\title{
Farklı Fertigasyon Teknikleri ve Su Kısıntısı Koșullarında Domates Bitkisinin Su Verim İlișkilerinin Belirlenmesi
}

\author{
1*Alper BAYDAR, $\quad$ 2Mustafa ÜNLÜ
}

'Alata Bahçe Kültürleri Araștırma Enstitüsü Müdürlüğü, alper.baydar@tarimorman.gov.tr ${ }^{2}$ Çukurova Üniversitesi Ziraat Fakültesi Tarımsal Yapılar ve Sulama Bölümü

\begin{abstract}
*Sorumlu yazar e-mail (Corresponding author e-mail): alper.baydar@tarimorman.gov.tr Geliș tarihi (Received) : 09.07.2020

Kabul tarihi (Accepted): 21.08 .2020

DOI: $10.21657 /$ topraksu.767185
\end{abstract}

Öz

Damla sulama sistemlerinde sulama suyu ve gübrenin birlikte uygulandığı fertigasyon tekniklerinin bașarısı gübrenin bitkiye iletim șekli ve konsantrasyonun zaman içerisindeki dağıımına bağlıdır. Özellikle iklimsel değișikliklerin su kaynakları üzerinde olumsuz etkileri dikkate alındığında, su kısıntısı koșulları ile birlikte gübreleme bitki gelișimi için daha da önemli bir hal almaktadır. Çalıșmada enjeksiyon pompası (F1), ventüri (F2) ve basınç farkı (F3) fertigasyon teknikleri ile $I_{100}, I_{70}$ ve $I_{50}$ sulama konularının domates bitkisinin su verim ilișkileri üzerindeki etkileri belirlenmiștir. 2014-2015 yılları arasında yapılan araștırmanın 2014 (birinci deneme yılı) sonuçlarına göre domates bitkisinde en yüksek verim F1 enjeksiyon pompası yöntemi ve $I_{100}$ tam sulama konusunda $4875 \mathrm{~kg} \mathrm{da}^{-1}$ olarak elde edilmiștir. F2 ventüri I ${ }_{100}$ tam sulama konusunda 584.7 mm șeklinde en yüksek mevsimlik bitki su tüketimi değeri elde edilirken, en yüksek sulama suyu miktarı 397.7 mm mm olarak I $_{100}$ tam sulama konularında tespit edilmiștir.

Anahtar Kelimeler: Bitki su tüketimi, domates, fertigasyon teknikleri, kısıntılı sulama, verim

\section{Determination of the Water Yields Relations Under Different Fertigation Techniques and Irrigation Deficit Conditions on Tomato}

\begin{abstract}
Success of the fertigation techniques on drip irrigation which water and fertilizer are used together depends on fertilizer concentration, distrubition and transmission type to crop in time. Especially, consideration of the adverse effects of the climate changes on water supplies, fertilization with deficit irrigation regimes is more important for plant growth. In this study effects of F1 injection pump, F2 venturi injector and F3 pressure diversity fertigation techniques with $I_{100}, I_{70}$ and $I_{50}$ irrigation treatments on tomato was determined. Results of the 2014 experiment year, the highest yield was obtained as 4875 $\mathrm{kg} \mathrm{da}^{-1}$ in $\mathrm{F} 1$ injection pump and $\mathrm{I}_{100}$ full irrigation treatments. The highest seasonal evapotranspiration was obtained as $584.7 \mathrm{~mm}$ in $\mathrm{F} 2$ venturi injector and $\mathrm{I}_{100}$ full irrigation treatments while the highest irrigation amount was $397.7 \mathrm{~mm}$ on $\mathrm{I}_{100}$ full irrigation treatments.
\end{abstract}

Keywords: Evapotranspiration, tomato, fertigation techniques, deficit irrigation, yield

\footnotetext{
*Damla sulama sistemlerinde kullanılan farkıı fertigasyon ekipmanlarının domates bitkisi üzerindeki etkilerinin incelenmesi isimli doktora tezinden alınmıștır
}

Alper BAYDAR: https://orcid.org/0000-0002-1426-466X

Mustafa ÜNLÜ: https://orcid.org/0000-0002-1889-516X 


\section{Giriș}

Domates bitkisi insan sağlığı ve beslenmesi açısından dünyada önemli bir yere sahiptir. FAO 2019 yılı verilerine göre domates bitkisinin yaklașık 182 milyon ton üretim miktarı ile dünyada üretimi en çok yapılan sebze olduğu bildirilmektedir. Ülkemiz ise yaklașık 12 milyon ton üretim ile Çin ve Hindistan'dan sonra üçüncü sırada yer almaktadır. Türkiye'de üretilen domatesin yaklașık \%20-30'u gıda sanayinde ișlenmekte, kalan miktar taze tüketime gitmektedir (Sarısaçli, 2009).

Damla sulama sistemlerinde kullanılan fertigasyon yöntemleri, gübrelerin bitki kök bölgesine eșit bir biçimde dağımasının yanında zaman ve iș gücü tasarrufu sağlaması nedeni ile dünyada yaygın șekilde kullanılmaktadır. Fertigasyonda kullanılan farklı ekipmanların gübreyi toprağa iletme șekilleri ve konsantrasyon dağılımları gübrelemenin bașarısı açısından büyük önem arz etmektedir. Günümüzde kullanılan fertigasyon ekipmanlarının çoğunun çalıșma prensibi gereği, konsantrasyon ve gübrenin zamansal dağıımını düzenleme olanakları bulunmamaktadır. Damla sulama sistemlerinde, gübrelerin sisteme sulama süresinin hangi zamanlarında ve miktarlarda verileceği ile kullanılacak olan doğru fertigasyon ekipmanlarının belirsizliği sistemin bașarııında dezavantaj olușturmaktadır.

Gelecek yıllarda iklimsel değișikliklerin tarımsal üretim açısından en olumsuz etkilerinin su kaynakları üzerinde olacağı yönünde çalıșmalar yapılmaktadır. Sıcaklık artıșından daha çok çölleșme tehdidi altındaki kurak ve yarı kurak bölgelerle, yeterli suya sahip olmayan Güneydoğu, iç Anadolu, Ege ve Akdeniz bölgeleri gibi yarı nemli bölgelerin etkilenmesi beklenmektedir (Öztürk, 2002). Bu anlamda bölgesel ve yerel ölçekte çalıșmalar önemini artırmaktadır. Olası su kaynakları üzerindeki olumsuz etkilere bağlı olarak tarımsal sulama yönünden daha az miktarda su kullanarak optimum verimi alabilmek amacı ile su kısıntısı koșulları ve tam sulama koșullarında domates bitkisinde verime dair çalıșmalar yapılmıștır. Özbahçe vd., (2012) ile Kırda vd., (2004) çalıșmalarında tam sulama konusunda en yüksek verimi elde etmișlerdir. Benzer șekilde Topçu vd., (2007) ve Shennan vd., (1991) yaptıkları araștırma sonuçlarına göre su kısıntısı koșullarında domates bitkisinde daha düșük verim değerleri olduğunu bildirmișlerdir.

\section{MATERYAL VE YÖNTEM}

\section{Materyal}

Deneme Alata Bahçe Kültürleri Araștırma Enstitüsü Müdürlüğü Tarsus Toprak ve Su Kaynakları Lokasyonu arazisinde yürütülmüștür. 2014 birinci yılı deneme alanı meteorolojik verileri Çizelge 1'de verilmiștir. Deneme alanı iklim istasyonu verilerine göre araștırmanın yürütüldüğü bölgede Akdeniz iklimi görülüp uzun yıllık yağıș ortalaması 601.8 mm'dir. Yılın en yağıșlı geçen ayları Kasım, Aralık, Ocak, Șubat, en kurak ayları ise Haziran, Temmuz, Ağustos ve Eylül'dür. Toplam yağıșın \%54'ü kıș aylarında düșmektedir. Yağıșın büyük bir bölümü yağmur șeklindedir. Bölgede uzun yıllık sıcaklık ortalaması $18.1^{\circ} \mathrm{C}$ dir. En sıcak ay ortalaması Temmuz'da $26.8^{\circ} \mathrm{C}$, en soğuk ay ortalaması Ocak'ta $9.8^{\circ} \mathrm{C}^{\prime}$ dir. Uzun yıllar ölçümlerine göre oransal nem ortalaması \%70.4, yıllık buharlașma ise $1479.9 \mathrm{~mm}$ 'dir.

Deneme alanının farklı noktalarından alınan bozulmuș ve bozulmamıș toprak örneklerinin analizi sonucunda toprağın bazı fiziksel (bünye, hacim ağırlığı, su tutma kapasitesi) ile kimyasal özellikleri (tuzluluk, anyonlar ve katyonlar, pH, organik madde, yarayıș ${ }_{1} \mathrm{P}_{2} \mathrm{O}_{5}$ ve $\mathrm{K}_{2} \mathrm{O}$ ) belirlenerek Çizelge 2. ve Çizelge 3'de verilmiștir.

Çizelge 1. Deneme alanı 2014 yllı iklim verileri

Table 1. Climate datas of experiment field in 2014

\begin{tabular}{|c|c|c|c|c|c|c|}
\hline \multirow{2}{*}{$\begin{array}{c}\text { İklim } \\
\text { Parametreleri }\end{array}$} & \multicolumn{6}{|c|}{ AYLAR } \\
\hline & Mart & Nisan & Mayıs & Haziran & Temmuz & Ağustos \\
\hline$\underset{{ }^{\circ} \mathrm{C}}{\text { Maksimum Sıcaklık, }}$ & 20.4 & 21.0 & 27.6 & 29.3 & 32.5 & 34.6 \\
\hline \multicolumn{7}{|l|}{ Minimum } \\
\hline Sicaklık, ${ }^{\circ} \mathrm{C}$ & 9.0 & 12.1 & 15.2 & 19.1 & 23.2 & 23.6 \\
\hline \multicolumn{7}{|l|}{ Ortalama } \\
\hline Sicaklık, ${ }^{\circ} \mathrm{C}$ & 14.0 & 15.5 & 21.2 & 23.9 & 27.1 & 28.7 \\
\hline Yağıș, mm & 70.2 & 8.0 & 30.4 & 1.3 & 1.4 & 8.2 \\
\hline
\end{tabular}


Çizelge 2. Deneme alanı topraklarının fiziksel özellikleri

Table 2. Physical properties of experiment field soils

\begin{tabular}{cccccccc}
\hline $\begin{array}{c}\text { Derinlik } \\
(\mathrm{cm})\end{array}$ & $\begin{array}{c}\text { Kum } \\
(\%)\end{array}$ & $\begin{array}{c}\text { Kil } \\
(\%)\end{array}$ & $\begin{array}{c}\text { Silt } \\
(\%)\end{array}$ & Bünye & $\begin{array}{c}\text { Tarla Kapasitesi } \\
\left(\mathrm{g} \mathrm{g}^{-1}\right)\end{array}$ & $\begin{array}{c}\text { Solma Noktası } \\
\left(\mathrm{g} \mathrm{g}^{-1}\right)\end{array}$ & $\begin{array}{c}\text { Hacim Ağırlığı } \\
\left(\mathrm{g} \mathrm{cm}^{-3}\right)\end{array}$ \\
\hline $0-30$ & 20.2 & 41.9 & 37.9 & C & 30.70 & 19.75 & 1.30 \\
$30-60$ & 15.9 & 42.0 & 42.1 & SC & 29.97 & 19.12 & 1.40 \\
$60-90$ & 11.7 & 44.1 & 44.3 & SC & 29.64 & 12.71 & 1.42 \\
\hline
\end{tabular}

Çizelge 3. Deneme alanı topraklarının kimyasal özellikleri

Table 3. Chemical properties of experiment field soils

\begin{tabular}{|c|c|c|c|c|c|c|}
\hline \multirow{2}{*}{$\begin{array}{l}\text { Derinlik } \\
(\mathrm{cm})\end{array}$} & \multirow{2}{*}{$\begin{array}{c}E C \\
\left(\mathrm{dS} \mathrm{m}^{-1}\right)\end{array}$} & \multirow[b]{2}{*}{$\mathrm{pH}$} & \multirow{2}{*}{$\begin{array}{c}\text { Kireç } \\
\% \\
\mathrm{CaCO}_{3}\end{array}$} & \multicolumn{2}{|c|}{ Yarayıșlı } & \multirow{2}{*}{$\begin{array}{l}\text { Organik Madde } \\
\qquad(\%)\end{array}$} \\
\hline & & & & $\mathrm{P}_{2} \mathrm{O}_{5}\left(\mathrm{~kg} d \mathrm{a}^{-1}\right)$ & $\mathrm{K}_{2} \mathrm{O}\left(\mathrm{kg} \mathrm{da}^{-1}\right)$ & \\
\hline $0-30$ & 0.914 & 7.91 & 21.78 & 1.9 & 134.32 & 1.80 \\
\hline $30-60$ & 0.976 & 7.97 & 28.30 & 0.9 & 68.49 & 1.06 \\
\hline $60-90$ & 1.028 & $8.0 \mathrm{w} 8$ & 24.80 & 0.5 & 43.01 & 0.77 \\
\hline
\end{tabular}

Araștırmada domates (solanum Iycopersicum) çeșidi olarak domates sarı yaprak kıvırcıklığı virüsüne ve Fusarium hastalığına dayanıklı Marmara F 1 çeșidi kullanılmıștır. Su kaynağı olarak deneme alanında mevcut derin kuyuda bulunan ve değerleri Q: $60 \mathrm{t}$ $\mathrm{h}^{-1}$ debi ve 50 mss manometrik yüksekliğe sahip ve $30 \mathrm{kw} \mathrm{h}^{-1}$ güce dalgıç pompadan yararlanılmıștır.

Çalıșmada F1 enjeksiyon pompası, F2 venturi ve F3 basınç farkı yöntemi ile çalıșan 3 farkı fertigasyon ekipmanı kullanılmıștır. Her ekipmanda gübreyi sisteme vermek amacıyla 100 L'lik gübre tankları kullanılmıs ve gerekli ek parçalar ile sisteme bağlantıları yapılımıștır. Günay (2005)'e göre saf olarak $16 \mathrm{~kg} \mathrm{da}^{-1}$ $\mathrm{N}, 5 \mathrm{~kg} \mathrm{da}^{-1} \mathrm{P}_{2} \mathrm{O}_{5}$ ve $23 \mathrm{~kg} \mathrm{da}^{-1} \mathrm{KNO}_{3}$ olacak șekilde parsellere gübre uygulaması yapılmıștır. Denemede gübreler $\mathrm{N}$; $\left(\mathrm{NH}_{4}\right)_{2} \mathrm{SO}_{4}, \mathrm{P}$; MKP ve $\mathrm{K}$; $\mathrm{KNO}_{3}$ formlarında uygulanmıștır. Toprak analiz sonuçlarına göre gerekli görüldüğü hallerde diğer kullanılabilir bitki besin elementlerinin verilmesi sağlanmıștır. Azot ve fosfor üçe bölünerek 1/3'ü dikim öncesi taban gübresi olarak, geri kalan kısımlar ise sulama tarihlerine göre bölünerek fertigasyon ekipmanları yardımı ile sulama sezonu süresince eșit miktarlarda verilmiștir. Yapılan araștırmada damla sulama sisteminden yararlanılarak infiltrasyon testi sonuçlarına göre $40 \mathrm{~cm}$ damlatıcı aralıklı ve $4 \mathrm{~L} \mathrm{~h}^{-1}$ debiye sahip, $1 \mathrm{~mm}$ et kalınlığında ve $\varnothing 16 \mathrm{~mm}$ dıș çapında içten geçik damlatıcıların olduğu lateraller kullanılmıștır.

\section{Yöntem}

Araștırmada 3 farklı sulama konusu ile 3 farklı fertigasyon ekipmanından olușan konular dikkate alınmıștır. Toprak suyu gözlemleri ise gravimetrik olarak 1 haftalık süre ile ölçülmüștür.
Sulama konularl;

$\mathrm{I}_{100}:$ Tam sulama konusu olup bir haftalık sulama aralığında $60 \mathrm{~cm}$ 'lik toprak profilindeki eksik nemin tarla kapasitesine getirildiği konu,

$I_{70}$ : Tam sulama konusuna uygulanan suyun \%70'inin verildiği konu,

$\mathrm{I}_{50}$ : Tam sulama konusuna uygulanan suyun $\% 50$ 'sinin verildiği konudur.

Denemede her 3 farklı fertigasyon konularına ait sulama düzeyleri aynı anda çalıștııımıș, aynı miktar ve çeșit gübreler sisteme verilerek her yöntemin kendi arasındaki durumları farklı sulama düzeyleri ile birlikte değerlendirilmiștir. Her fertigasyon ve sulama konularından sonra gübre tankları belirlenen miktarda gübreler ile diğer sulama konularında çalıștırımıștır.

Uygulanan sulama suyu miktarı așağıdaki gibi belirlenmiștir,

$$
\mathrm{IR}=A^{*} P^{*} \Delta S
$$

Burada;

IR : Sulama suyu miktarı, L
A : Parsel alanı, $\mathrm{m}^{2}$
P : Islatılan alan yüzdesi, \%

$\Delta \mathrm{s}$ : $60 \mathrm{~cm}$ derinlikteki eksik toprak su içeriği, mm

Islatılan alan yüzdesi sulama aralıklarında örtü yüzdesi olarak izlenmiș ve örtü genișliğinin sıra arası uzaklığa oranlanmasıyla ıslatma yüzdesi hesaplanmıștır. 
Çizelge 4. Fertigasyon konularında ve farklı sulama düzeylerinde uygulanan sulama suyu miktarları, mm

Table 4. Applied irrigation water amounts in fertigation treatments and different irrigation levels, $\mathrm{mm}$

\begin{tabular}{|c|c|c|c|c|c|c|c|c|c|}
\hline \multirow[t]{2}{*}{ Tarih } & \multicolumn{3}{|c|}{$\mathrm{Fl}$} & \multicolumn{3}{|c|}{$\mathrm{F} 2$} & \multicolumn{3}{|c|}{ F3 } \\
\hline & $I_{10}$ & $\mathrm{I}_{70}$ & $I_{50}$ & $I_{100}$ & $\mathrm{I}_{70}$ & $I_{50}$ & $I_{100}$ & $\mathrm{I}_{70}$ & $\mathrm{I}_{50}$ \\
\hline 1.04 .2014 & 15.0 & 15.0 & 15.0 & 15.0 & 15.0 & 15.0 & 15.0 & 15.0 & 15.0 \\
\hline 3.04 .2014 & 15.0 & 15.0 & 15.0 & 15.0 & 15.0 & 15.0 & 15.0 & 15.0 & 15.0 \\
\hline 9.04 .2014 & 8.7 & 8.7 & 8.7 & 8.7 & 8.7 & 8.7 & 8.7 & 8.7 & 8.7 \\
\hline 17.04 .2014 & 11.2 & 11.2 & 11.2 & 11.2 & 11.2 & 11.2 & 11.2 & 11.2 & 11.2 \\
\hline 2.05 .2014 & 33.0 & 33.0 & 33.0 & 33.0 & 33.0 & 33.0 & 33.0 & 33.0 & 33.0 \\
\hline 18.05 .2014 & 25.2 & 17.6 & 12.6 & 25.2 & 17.6 & 12.6 & 25.2 & 17.6 & 12.6 \\
\hline 25.05 .2014 & 38.7 & 27.0 & 19.3 & 38.7 & 27.0 & 19.3 & 38.7 & 27.0 & 19.3 \\
\hline 1.06 .2014 & 50.0 & 35.0 & 25.0 & 50.0 & 35.0 & 25.0 & 50.0 & 35.0 & 25.0 \\
\hline 8.06 .2014 & 44.5 & 31.2 & 22.2 & 44.5 & 31.2 & 22.2 & 44.5 & 31.2 & 22.2 \\
\hline 15.06 .2014 & 46.9 & 32.8 & 23.4 & 46.9 & 32.8 & 23.4 & 46.9 & 32.8 & 23.4 \\
\hline 22.06 .2014 & 51.0 & 35.7 & 25.5 & 51.0 & 35.7 & 25.5 & 51.0 & 35.7 & 25.5 \\
\hline 29.06 .2014 & 58.5 & 40.9 & 29.2 & 58.5 & 40.9 & 29.2 & 58.5 & 40.9 & 29.2 \\
\hline TOPLAM & 397.7 & 303.1 & 240.1 & 397.7 & 303.1 & 240.1 & 397.7 & 303.1 & 240.1 \\
\hline
\end{tabular}

Deneme tesadüf bloklarında bölünmüs parseller deneme desenine göre 3 tekerrürlü olarak yürütülmüștür. Fertigasyon ekipmanları ana parselleri (3 konu), sulama konuları ( 3 konu) ise alt parselleri olușturmuștur. Her parselde 5 sıra olacak șekilde, sıra üzeri $0.5 \mathrm{~m}$ ve sıra arası $1.2 \mathrm{~m}$ olup, her parselin uzunluğu $20 \mathrm{~m}$ ve alanı $4.8 \mathrm{~m}$ x $20 \mathrm{~m}$ $=96 \mathrm{~m}^{2}$ dir.

Araștırmada bitki su tüketimi (Evapotranspirasyon) su bütçesi eșitliği ile belirlenmiștir: (Howell vd., 1986)

$\mathrm{ET}=1+\mathrm{Pe}+\mathrm{Cr}+\mathrm{Dp}+\mathrm{Rf}+\Delta \mathrm{s}$

Burada;

ET: Bitki su tüketimi, mm

I: Uygulanan sulama suyu, mm

Pe: Etkili yağıș, mm

Cr: Kılcal yükseliș, mm

Dp: Derine sızma kayıpları, mm

Rf: Yüzey akıș kayıpları, mm

$\Delta s$ : Etkili kök bölgesindeki toprak suyu değișimi, mm

Dıșarıdan parsel içlerine su girișini önlemek için her bir parselin etrafı seddelerle çevrilmiștir. Eșitliklerde belirtilen kılcal yükseliș, derine sızma ve yüzey akıș değerleri, damla sulama yönteminden ötürü ayrıca eksiknemin tarla kapasitesine getirilerek sulama uygulamasından yararlanıldığı için sıfır olarak kabul edilmiștir. Her sulama ve fertigasyon konularında verim değerlerini elde edebilmek amacı ile ilk hasattan son hasada kadar her tekerrür ve uygulamadan alınan meyveler kümülatif olarak toplanarak toplam meyve verimi elde edilmiștir. Kenar tesiri etkilerini ortadan kaldırmak amacıyla her parselden 10 m uzunluğundaki orta sıralar hasat edilmiștir.

Denemenin 2014 yılında Marmara F1 domates çeșidi araziye 01.04.2014 tarihinde dikimi yapıldıktan sonra tüm parsellere eșit miktarda 5 kez can suyu uygulaması bitkiler toprağa dirençli olana dek uygulanmıștır.

\section{BULGULAR VE TARTIȘMA}

Her üç fertigasyon konusunda (F1, F2 ve F3) konusunda üç farklı sulama düzeyinde $\left(_{100}, I_{70}\right.$ ve $\left.I_{50}\right) 2014$ yilında toplamda 12 konulu sulama uygulamaları yapılmıștır. F1, F2 ve F3 konularında üç farklı sulama düzeylerinde verilen toplam sulama suyu miktarları 397.7 - $240.1 \mathrm{~mm}$ arasında değișmiștir. Her üç fertigasyon konularına yapılan sulama uygulamaları tarihleri ve miktarları Çizelge 4'de gösterilmiștir.

Araștırmanın 2014 deneme yılında bitki su tüketiminin hesaplanmasında su dengesi eșitliği kullanılmıștır (Howell vd., 1986). Bahsi geçen eșitlikte büyüme sezonu boyunca yağıș miktarı ve toprak nem içeriği dikkate alınmıștır. Domates bitkisinde ekimden hasata kadar olan dönem boyunca hesaplanan mevsimlik bitki su tüketim değerleri, bitkilerin dikim ve son hasat tarihlerinde 
Çizelge 5. Sulama suyu miktarı, yağıș, nem ve ET değerleri

Table 5. Amounts of irrigation water, rainfall, humidity and ET values

\begin{tabular}{ccccccc}
\hline & Sulama Konuları & $\begin{array}{c}\text { Sulama Suyu } \\
\text { Miktarı, mm }\end{array}$ & Yağıș, mm & $\begin{array}{c}\text { Bașlangıç } \\
\text { Nemi, mm }\end{array}$ & $\begin{array}{c}\text { Bitiș Nemi, } \\
\mathrm{mm}\end{array}$ & ET, mm \\
\hline \multirow{3}{*}{$F_{1}$} & $\mathrm{I}_{100}$ & 397.7 & 114 & 232 & 165 & 578.7 \\
& $\mathrm{I}_{70}$ & 303.1 & 114 & 232 & 155 & 494.1 \\
& $\mathrm{I}_{50}$ & 240.1 & 114 & 232 & 148 & 438.1 \\
\hline \multirow{3}{*}{$F_{2}$} & $\mathrm{I}_{100}$ & 397.7 & 114 & 232 & 159 & 584.7 \\
& $\mathrm{I}_{70}$ & 303.1 & 114 & 232 & 150 & 499.1 \\
& $\mathrm{I}_{50}$ & 240.1 & 114 & 232 & 143 & 443.1 \\
\hline \multirow{3}{*}{$F_{3}$} & $\mathrm{I}_{100}$ & 397.7 & 114 & 232 & 161 & 582.7 \\
& $\mathrm{I}_{70}$ & 303.1 & 114 & 232 & 152 & 497.1 \\
& $\mathrm{I}_{50}$ & 240.1 & 114 & 232 & 145 & 441.1 \\
\hline
\end{tabular}

belirlenen toprak nemi değerleri sırası ile Çizelge 5'de verilmiștir. Mevsimlik bitki su tüketimi değerleri 2014 yılı için sulama konularına göre F1 konusunda 438.1-578.7 mm, F2 konusunda 443.1-584.7 mm ve F3 konusunda 441.1-582.7 mm arasında değișmiș ve büyüme mevsimi süresince gerçekleșen yağıș miktarı 114 mm olmuștur.

Denemede farklı fertigasyon konuları ve sulama düzeylerine ait toplam verim değerleri Çizelge 6'da verilmiștir. Çizelge 6. incelendiğinde domatesin toplam verim değerleri 2803 - 4875 $\mathrm{kg} \mathrm{da}^{-1}$ arasında değișmiștir. Enjeksiyon pompası olan fertigasyon yönteminde (F1) toplam verim değerleri 3660 - $4875 \mathrm{~kg} \mathrm{da}^{-1}$ arasında, venturi olan fertigasyon yönteminde (F2) 2803

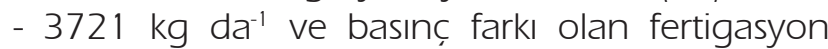
yönteminde (F3) 3760 - $4514 \mathrm{~kg} \mathrm{da}^{-1}$ olduğu belirlenmiștir. Yapılan varyans analizi sonuçlarına

Çizelge 6. Farklı fertigasyon yöntemleri ve sulama düzeylerinin domates verimine etkileri

Table 6. Effects of different fertigation methods and irrigation levels on tomato yield

\begin{tabular}{ccc}
$\begin{array}{c}\text { Fertigasyon } \\
\text { Konularl }\end{array}$ & $\begin{array}{c}\text { Sulama } \\
\text { Düzeyleri }\end{array}$ & $\begin{array}{c}\text { Domates Verimi } \\
\mathrm{kg} \mathrm{da}^{-1}\end{array}$ \\
\hline \multirow{2}{*}{$\mathrm{Fl}$} & $\mathrm{I}_{100}$ & 4875 \\
& $\mathrm{I}_{70}$ & 4049 \\
& $\mathrm{I}_{50}$ & 3660 \\
\hline \multirow{F}{*}{$\mathrm{F} 2$} & $\mathrm{I}_{100}$ & 3721 \\
& $\mathrm{I}_{70}$ & 2840 \\
& $\mathrm{I}_{50}$ & 2803 \\
\hline $\mathrm{F3}$ & $\mathrm{I}_{100}$ & 4514 \\
& $\mathrm{I}_{70}$ & 4263 \\
& $\mathrm{I}_{50}$ & 3760 \\
\hline
\end{tabular}

göre fertigasyon yöntemi, sulama konuları ve fertigasyon*sulama konuları interaksiyonu verim üzerine etkileri istatistiksel olarak \%1 düzeyinde önemli bulunmuștur. Ortalama toplam verimlerin LSD gruplandırması Çizelge 7'de verilmiștir. LSD gruplandırması sonucuna göre en yüksek verim enjeksiyon pompası ile fertigasyon yönteminin uygulandığı (Fl) $\left.\right|_{100}$ konusunda $4875 \mathrm{~kg} \mathrm{da}^{-1}$ olarak belirlenmiștir. En düșük verim değerleri ise venturi fertigasyon yönteminin uygulandığı (F2) $I_{50}$ konusundan $2803 \mathrm{~kg} \mathrm{da}^{-1}$ ve (F2) $\mathrm{I}_{70}$ konusundan $2840 \mathrm{~kg} \mathrm{da}^{-1}$ olarak elde edilmiștir. Basınç farkı yönteminin uygulandığı fertigasyon yönteminde (F3) en yüksek verim I ${ }_{100}$ konusunda $4514 \mathrm{~kg} \mathrm{da}^{-1}$ olduğu sonucuna varılmıștır.

Çizelge 7. Fertigasyon ve sulama konularının verime ilișkin LSD gruplandırması

Table 7. LSD group of fertigation and irrigations treatments relating to yield

\begin{tabular}{cccc}
\hline \multirow{2}{*}{$\begin{array}{c}\text { Fertigasyon } \\
\text { Yöntemi(F) }\end{array}$} & \multicolumn{3}{c}{ Sulama Konuları (SK) } \\
\cline { 2 - 4 } $\mathrm{I}_{100}$ & $\mathrm{I}_{70}$ & $\mathrm{I}_{50}$ \\
\hline $\mathrm{F}_{1}$ & $4875 \mathrm{a}$ & $4049 \mathrm{~d}$ & $3660 \mathrm{e}$ \\
$\mathrm{F}_{2}$ & $3721 \mathrm{e}$ & $2840 \mathrm{f}$ & $2803 \mathrm{f}$ \\
$\mathrm{F}_{3}$ & $4514 \mathrm{~b}$ & $4263 \mathrm{C}$ & $3760 \mathrm{e}$ \\
$\begin{array}{c}\text { Istatistiksel } \\
\text { Analiz }\end{array}$ & $\mathrm{F}$ *SK: LSD $(0.05)=203.3 ; \mathrm{P}=0.01 * *$ \\
\hline
\end{tabular}

Sulama suyu miktarları $I_{100}-I_{70}$ ve $_{50}$ konularında sırası ile 397.7, 303.1, 240.1 mm olarak belirlenmiștir. Kısıntılı sulama koșullarında sulama suyu miktarlarının azaldığı belirlenmiștir. Mevsimlik su tüketimleri sulama konularına göre 441.4 584.9 mm arasında değiștiği belirlenmiștir. 


\section{SONUC̣LAR}

Domates bitkisinde her fertigasyon konularında, tam sulama uygulanan konulardan en yüksek verimler elde edilmiș ve su kısıntısı arttıkça verimde azalmalar belirlenmiștir . Araștırmada dikkate alınan fertigasyon yöntemlerinden enjeksiyon pompası yönteminde (F1) ve $I_{100}$ (tam sulama) konusunda $4875 \mathrm{~kg} \mathrm{da}^{-1}$ ile en yüksek verim elde edilirken en düșük verim değeri ise ventüri yöntemi (F2) ve $I_{50}$ (kısıntılı sulama) konusunda 2803 kg da-1 olarak belirlenmiștir.

Yapılan bu araștırmada bitki besin elementlerinin bitkilere uygulandığı en yaygın yöntemlerden olan fertigasyon teknikleri ve su kısıntısı koșullarının domates bitkisi üzerindeki etkileri incelenmiștir. Araștırmada kullanılan her üç fertigasyon ekipmanı da günümüzde damla sulama sistemlerinde yaygın olarak kullanılmaktadır. Çalıșma sonucuna göre enjeksiyon pompası yöntemi, diğer fertigasyon tekniklerine göre domates bitkisinde daha yüksek verim elde edilmesini sağlamıștır. Ventüri ve basınç farkı yöntemleri gübreleri istenilen konsantrasyon ve miktarlarda bitki kök bölgesine gönderememekte ve bu durum verim değerlerine etki etmektedir. Ventüri tekniğinde diğer tekniklere göre daha yüksek bitki su tüketimi değerleri elde etmiștir. Domates bitkisinde tam sulama yapılması verim ve kalite yönünden daha avantajlı da olsa önümüzdeki yıllarda su kaynakları üzerinde olası olumsuz etkiler bu durumu kısıtlamaktadır.

\section{KAYNAKLAR}

FAO (2009). Statistical database. Available: http:// www. fao.org. (02.12.2019)

Günay A (2005). Özel sebze yetiștiriciliği II. bölüm, domates yetiștiriciliği. 318-343

Howell TA, Musick JT, Tolk JA (1986). Canopy temperature of irrigated winter wheat. Transactions of the Asae, USA, 29(6):1692-1699

Kırda C, Çetin M, Dașgan Y, Topçu S, Kaman H, Ekici B, Derici MR, Özgüven Al (2004). Yield response of greenhouse grown tomato to partial root drying and conventional deficit irrigation. Agricultural Water Management, Adana, 69: 191 -201 .

Özbahçe A, Tarı AF, Cetin Ö (2012). Toprak nemi izlenerek olușturulan sulama programından uygun pan katsayısının tahmini: domates örneği. 9. Sebze Tarımı Sempozyumu, Konya, 399-406.

Öztürk K (2002). Küresel iklim değișikliği ve Türkiye'ye olası etkileri. G.Ü. Gazi Eğitim Fakültesi Dergisi, 22:47-65.

Sarısaçlı IE (2009). Salça. Available: http:// www.igeme. gov.tr, Erișim Tarihi 20.07.2009.

Shennan C, Mitchell JP, Grattan SR, May DM (1991). Tomato fruit yields and quality under water deficit and salinity. Journal of the American Society for Horticultural Science, California, 116(2):215-221.

Topçu S, Kırda C, Dașgan Y, Kaman H, Çetin M, Yazıcı A, Baco, MA (2007). Yield response and n-fertiliser recovery of tomato grown under deficit irrigation. European Journal of Agronomy, Adana, 26:64-70. 